\title{
OPEN Metabolite activity in the anterior cingulate cortex during a painful stimulus using functional MRS
}

\author{
J. Archibald ${ }^{1,2}$, E. L. MacMillan ${ }^{6,7,8}$, C. Graf ${ }^{1,9}$, P. Kozlowski $i^{1,5,6,10}$, C. Laule ${ }^{1,5,6,9,10,11}$ \& \\ J. L. K. Kramer ${ }^{1,3,4,5}$
}

To understand neurochemical brain responses to pain, proton magnetic resonance spectroscopy $\left({ }^{1} \mathrm{H}-\mathrm{MRS}\right)$ is used in humans in vivo to examine various metabolites. Recent MRS investigations have adopted a functional approach, where acquisitions of MRS are performed over time to track taskrelated changes. Previous studies suggest glutamate is of primary interest, as it may play a role during cortical processing of noxious stimuli. The objective of this study was to examine the metabolic effect (i.e., glutamate) in the anterior cingulate cortex during noxious stimulation using fMRS. The analysis addressed changes in glutamate and glutamate + glutamine (Glx) associated with the onset of pain, and the degree by which fluctuations in metabolites corresponded with continuous pain outcomes. Results suggest healthy participants undergoing tonic noxious stimulation demonstrated increased concentrations of glutamate and Glx at the onset of pain. Subsequent reports of pain were not accompanied by corresponding changes in glutamate of Glx concentrations. An exploratory analysis on sex revealed large effect size changes in glutamate at pain onset in female participants, compared with medium-sized effects in male participants. We propose a role for glutamate in the ACC related to the detection of a noxious stimulus.

Non-invasive neuroimaging techniques are widely applied to gain a deeper understanding of pain in health and disease $\mathrm{e}^{1-3}$. These approaches primarily focus on function by way of acquiring electroencephalography (EEG) ${ }^{4-8}$, magnetoencephalography (MEG) $)^{5,9,10}$, and functional magnetic resonance imaging (fMRI) $)^{11-14}$, and have yielded unprecedented insights into the temporal and spatial representation of pain in the brain. Despite major advances, knowledge regarding central mechanisms of pain is incomplete, highlighting a major need to develop techniques suitable for application in humans.

Since the late 1980s, magnetic resonance spectroscopy (MRS) has been employed as a non-invasive tool to quantify various metabolite levels in vivo in the brain, including n-acetyl-aspartate (NAA), total creatine (tCr), myo-inositol (mI), glutamate, and glutamine ${ }^{15}$. More recent investigations have adopted a "functional" approach, whereby acquisitions of MRS are performed in series, over time, to track task-related changes in metabolite levels ${ }^{16-23}$. The theoretical advantage of functional MRS is the potential to more directly measure local events and underlying metabolic processes ${ }^{16,19,22,24}$. This addresses a well-known limitation of conventional neuroimaging techniques, which reflect global activations and deactivations without a direct link to the underlying metabolic processes. In fMRS there is an intriguing opportunity to gain new insights into mechanisms underlying the processing of pain in the brain.

Several corresponding lines of evidence suggest that glutamate is a candidate biomarker for pain ${ }^{19,22,25-32}$. In addition to previous fMRS studies showcasing increased glutamate in response to acutely painful stimulation ${ }^{16,33-35}$, concentrations are altered in patient populations with chronic pain ${ }^{22,36-38}$. Emerging evidence also suggests that pharmacological approaches targeting glutamate receptors are effective in relieving acute ${ }^{39}$ and chronic pain ${ }^{30,39,40}$. Glutamine is another intriguing candidate. Synthesized from glutamate, glutamine is

${ }^{1}$ International Collaboration on Repair Discoveries (ICORD), University of British Columbia, Vancouver, Canada. ${ }^{2}$ Department of Experimental Medicine, University of British Columbia, Vancouver, Canada. ${ }^{3}$ Department of Anesthesiology, Pharmacology and Therapeutics, Faculty of Medicine, University of British Columbia, Vancouver, Canada. ${ }^{4}$ Djavad Mowafaghian Center for Brain Health (DMCH), Vancouver, Canada. ${ }^{5}$ Hughill Center, Vancouver, Canada. ${ }^{6}$ Department of Radiology, University of British Columbia, Vancouver, Canada. ${ }^{7}$ ImageTech Lab, Simon Fraser University, Surrey, Canada. ${ }^{8}$ Philips Healthcare Canada, Markham, Canada. ${ }^{9}$ Department of Physics and Astronomy, University of British Columbia, Vancouver, Canada. ${ }^{10}$ UBC MRI Research Centre, University of British Columbia, Vancouver, Canada. ${ }^{11}$ Pathology and Laboratory Medicine, University of British Columbia, Vancouver, Canada. ${ }^{\square}$ email: jessica.archibald@ubc.ca 
produced in the astrocytes and is an important, intermediary component of metabolism (i.e., glutamate-glutamine neurotransmission cycle $)^{41}$. Unfortunately, the similarity of chemical structures results in overlapping ${ }^{1} \mathrm{H}$ NMR spectra at $3 \mathrm{~T}^{41}$. As the separation of these is unreliable, the sum (referred to as Glx) can be quantified with higher accuracy ${ }^{41}$.

Among brain regions widely ascribed a role in pain $^{11,42-45}$, the anterior cingulate cortex (ACC) is ideally positioned and composed to acquire high-quality fMRS data. This relates to voxel placement away from air/tissue interfaces and bone (i.e., scalp) ${ }^{15}$ and high gray matter concentration to detect metabolites characterized by low signal to noise (e.g., glutamate) ${ }^{46}$. Seminal studies applying fMRS have yielded mixed results with regards to the metabolic effect of noxious stimulation in the ACC, including no change $e^{4-50}$ or increased glutamate and Glx levels ${ }^{16,21,33,34,51}$.

To examine glutamate in the ACC during noxious stimulation, we performed a study in healthy subjects using fMRS. A model of pain was used to generate tonic heat pain, during which participants rated their perceived intensity. Our analysis addressed changes in glutamate and Glx associated with the onset of pain, and the degree by which fluctuations in metabolites corresponded with continuous pain outcomes. We hypothesized that glutamate concentrations in the ACC would increase and track ratings throughout the continuous presentation of tonic heat, reflecting a prominent role in processing pain.

\section{Methods}

Subjects. Eighteen healthy participants $(9 \mathrm{~F} / 9 \mathrm{M}$, mean age $=26.28, \mathrm{SD}=3.68$, range $=21-36$ years $)$ were recruited to our study. Each provided informed consent and completed a general health questionnaire. The experimental protocol was explained to each participant in detail before testing. All procedures conformed to the Declaration of Helsinki and were approved by the Research Ethics Board of the University of British Columbia.

MR experiments. Data were collected using a $3 \mathrm{~T}$ Philips Achieva scanner (Best, Netherlands) with a single-channel Transmit-Receive (T/R) head coil. Participants' heads were immobilized using foam wedges. Sequences included:

(1) 3D T1 (MPRAGE, TE/TR/TI = 3.5/7.7/808 ms, shot interval $=1800 \mathrm{~ms}, 1 \mathrm{~mm}^{3}$ isotropic resolution, FOV $(\mathrm{ap} / \mathrm{rl} / \mathrm{fh})=256 / 200 / 150 \mathrm{~mm}^{3}$, scan time $\left.=5: 47\right)$.

(2) ${ }^{1} H$-MRS (PRESS, baseline: TE/TR $=22 / 4000 \mathrm{~ms}, \mathrm{NSA}=32$, scan time $=3: 12$, and 16 non-water suppressed spectra were acquired; functional: $\mathrm{TE} / \mathrm{TR}=22 / 4000 \mathrm{~ms}, \mathrm{NSA}=16$, scan time $=22: 4$; ACC, voxel size $=30 / 25 / 15 \mathrm{~mm}^{3}=11.2 \mathrm{~mL}$, 2nd order shimming, 16-step phase cycle with water suppression using the Excitation option- a Philips variant of $\mathrm{CHESS}^{52}$; a non-water suppressed acquisition preceded each complete phase-cycle for absolute metabolite quantification ${ }^{41,53}$ and water signal monitoring, Fig. 1A).

(3) $T_{2}$-weighted $\left(\mathrm{TE} / \mathrm{TR}=90 / 2000 \mathrm{~ms}\right.$, FOV $(\mathrm{ap} / \mathrm{rl} / \mathrm{fh})=250 / 189 / 36 \mathrm{~mm}^{3}$, resolution $=1 \times 1 \times 3 \mathrm{~mm}^{3}$, scan time $=0.32 \mathrm{~s}$ ) acquired before and after the fMRS scan to examine for possible subject motion and confirm stability of voxel placement. (See Fig. 2 for summary).

Pain stimulation paradigm. To reduce novelty effects associated with our model of experimental pain in the scanner subjects underwent a familiarization period one week prior to acquiring MR data. The same experimental pain procedures (outlined below) performed during MRS acquisition were performed in a laboratory setting.

The pain model was developed in preliminary testing and consisted of the application of $0.075 \%$ topical capsaicin and heat activation via thermo-pad on the volar surface of the right forearm $(\sim 8 \times 5 \mathrm{~cm})$. Capsaicin was applied immediately after baseline acquisition of MRS alongside a neutral thermo-pad without removing participants from the scanner. The thermo-pad was fixed to the skin and covered the area where capsaicin was applied, and activated by the influx of hot water via plastic tubing conveyed via the penetration panel. A nonheat conducting flexible brace was used to fasten the position of the thermo-pad (Fig. 3). The functional MRS followed by acquiring 16 shots every $1.08 \mathrm{~min}$ (total $=22.4 \mathrm{~min}$ ). After $9 \mathrm{~min}$, the thermo-pad was activated by circulating heated water to reach a temperature of approximately $41{ }^{\circ} \mathrm{C}$ at the forearm. Capsaicin was heatactivated for a period of $4.4 \mathrm{~min}$ ("heat"). Functional MRS was acquired continuously during heat application and for the reminder of the scan after the heat was removed (i.e., "post heat").

Pain intensity ratings. Participants were visually prompted for a pain intensity rating (using the $0-10$ numeric rating scale [NRS-11]) every 2 min during the functional MRS scan. Participants indicated an increase, decrease, or no change in perceived pain via an MRI compatible clicker. Feedback was provided by Presentation software (www.neurobs.com/presentation), allowing for the collection of pain ratings throughout the fMRS acquisition while avoiding verbal communication with subjects and head motion. Before commencing with the experimental procedure, participants were familiarized with the rating device.

Data pre-processing and quantification of metabolites. 3D T1 data was segmented into white matter, gray matter and cerebrospinal fluid using FSL BET and FAST ${ }^{54}$. Individual FIDs were pre-processed (eddy current correction, phase correction, frequency alignment, and visual inspection- for quality assurance) in MATLAB (R2016b) using in-house code. 32 shots were averaged for each 2-min block, yielding a total of 11 spectra analyzed using LCModel (v6.3-1H) (Fig. 1B). The simulated basis set was obtained from Steven Provencher specific for the echo time and field strength of this study. LCModel fitting was optimized between 0.2 and $4.2 \mathrm{ppm}$. The corresponding interleaved non-water suppressed spectra and each participant's brain tissue water volumes were used to calculate the concentration of NAA, tCr, glutamate and Glx in millimolar $(\mathrm{mM})^{53,55-57}$. Individual 


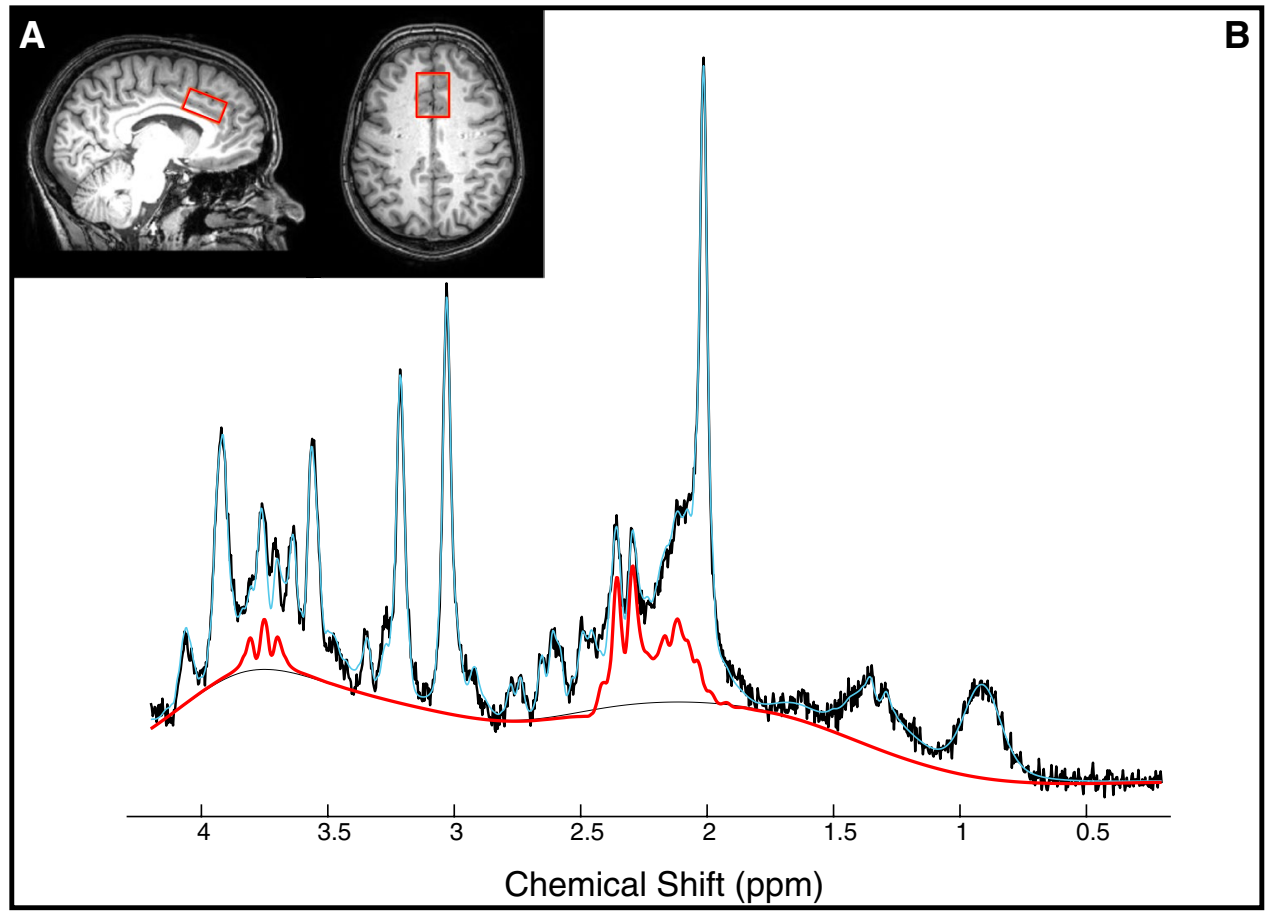

Figure 1. Glutamate levels in the anterior cingulate cortex (ACC). (A) Location of MRS voxel in the ACC. (B) Example spectrum with raw data (black), LCModel fit (blue), and the contribution of glutamate determined by LCModel (shown in red).
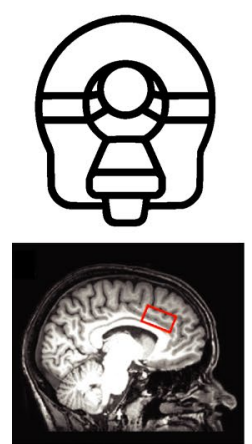

3DT1

MPRAGE, $\mathrm{TE} / \mathrm{TR} / \mathrm{TI}=$ 3.5/7.7/808ms, shot interval= $1800 \mathrm{~ms}, 1 \mathrm{~mm}^{3}$ isotropic resolution, $\mathrm{FOV}(\mathrm{ap} / \mathrm{rl} / \mathrm{fh})=$ $256 / 200 / 150 \mathrm{~mm}^{3}$

\section{Baseline MRS}

Single voxel PRESS Voxel $=30 / 25 / 15 \mathrm{~mm}^{3}$ $=11.2 \mathrm{~mL}, \mathrm{NSA}=32+$ 16 water reference acquisitions. 2nd order shimming, 16-step phase cycle with wate suppression using Excitation.
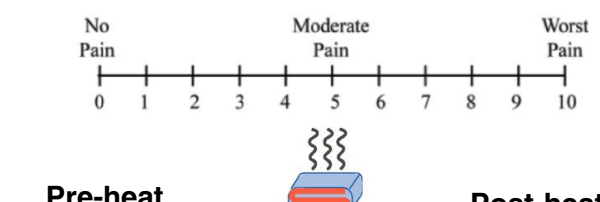

Pre-heat
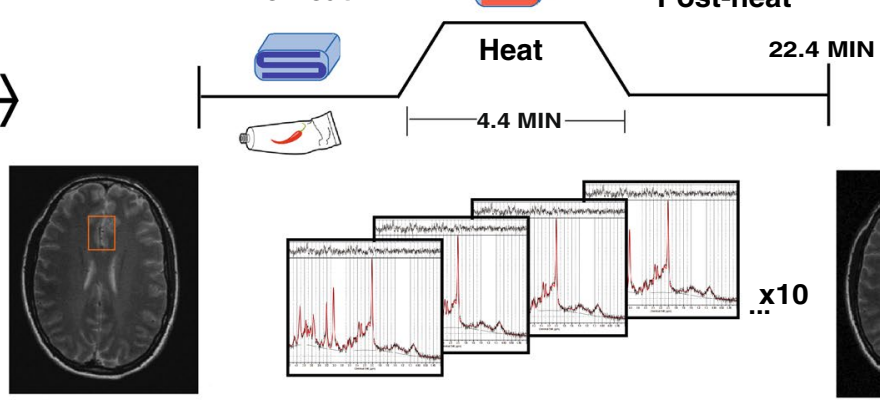

T2

Weighted image acquired before the fMRS scan. TE/TR=90/2000ms, FOV $(\mathrm{ap} / \mathrm{rl} / \mathrm{fh})=$ 250/189/36 $\mathrm{mm}^{3}$, resolution= $1 \times 1 \times 3 \mathrm{~mm}^{3}$

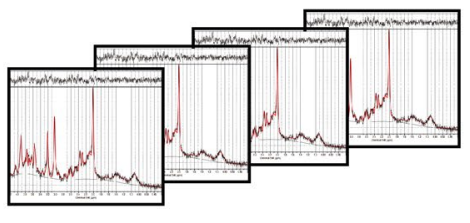

Functional MRS

20 functional blocks, each with 1 water and 16 acquired spectra scan time $=22: 4$.

The non-water suppressed acquisition preceded each complete phase-cycle for absolute metabolites quantification.

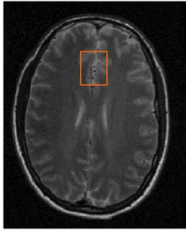

T2

Weighted image after fMRS scan to confirmabsence of motion and stability of the voxel

Figure 2. MR data acquisition and pain intervention. The functional scan was uninterrupted for $22.4 \mathrm{~min}$. Participants provided pain ratings via an MRI compatible clicker every $2 \mathrm{~min}$. $\mathrm{T}_{2}$-weighted images were acquired before and after the functional MRS scan series to confirm stability of voxel placement by absence of subject motion. 


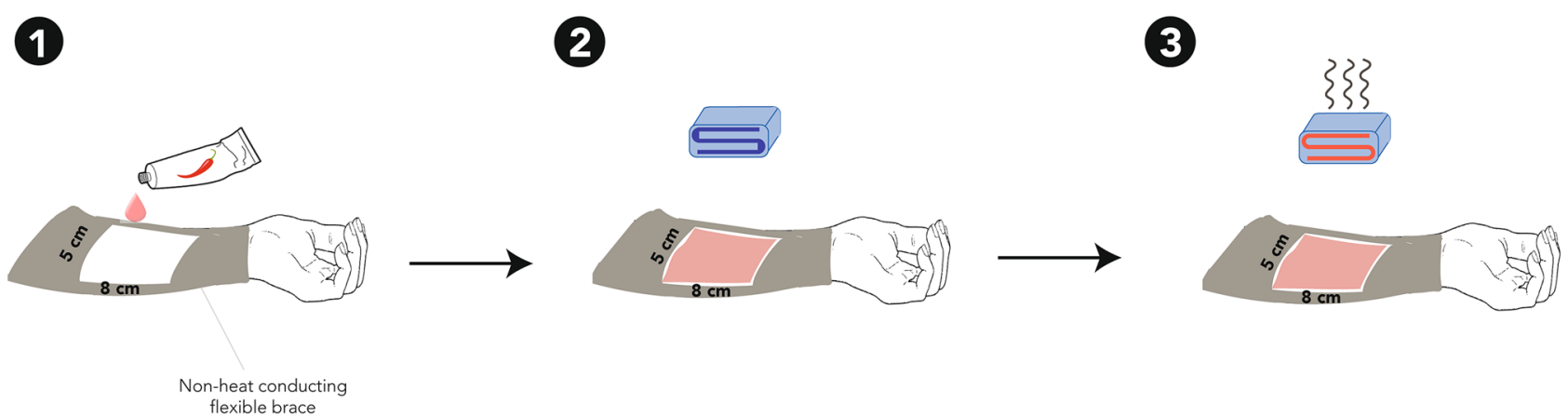

Figure 3. In-scanner pain model. (1) Capsaicin (0.075) was applied on the skin. (2) An inactive thermo-pad was placed on the skin covering the area where capsaicin was applied. 3) The thermo-pad was water-activated $\left(\sim 41^{\circ} \mathrm{C}\right)$.

water FID's were fitted to a single-exponential decay curve to extrapolate the water amplitude and the FID decay rate $\left(\mathrm{T} 2^{*}\right)$. This analysis was performed to assure the water amplitude and decay constants were unaffected by BOLD effects.

Statistical analysis. As a first step, a paired t-test was performed to determine changes in NAA, tCr, glutamate and Glx at the onset of pain. Pain onset was defined as a NRS score $\geq 2$ and was compared to the preceding concentration. To assess the specificity of glutamate and Glx, changes in NAA and $\mathrm{tCr}$ concentrations were also examined. Water amplitude and $\mathrm{T} 2^{*}$ stability during rest and pain onset were examined via a paired $\mathrm{t}$-test and effect sizes were calculated. A Pearson correlation was performed between the change in glutamate and Glx concentrations (rest vs pain-onset) and the corresponding pain ratings. An exploratory analysis examined the effects of sex with paired t-tests. Effect sizes were calculated using Cohen's $\mathrm{d}^{58}$ ( (small effect: $\mathrm{d}=0.2$, medium effect: $\mathrm{d}=0.5$, large effect: $\mathrm{d}=0.8$ ).

A linear mixed effects model was performed (using the R package lme4 Bates, Maechler \& Bolker, 2012) to determine the relationship between glutamate or Glx concentrations and pain intensity ratings over the entire duration of the scan. The statistical model included random slopes and intercepts, as well as the fixed effect of pain ratings $[$ Model $=\operatorname{lmer}([$ Glutamate $]$ or $[$ Glx $] \sim$ PainRating $+($ PainRating $\mid$ Subject $))]$. All statistical tests were performed at an a level of 0.05 in $\mathrm{R}$ (version 1.1.442, R Core Team 2012).

\section{Results}

One participant (f) that underwent the familiarization phase was unable to be scanned due to MR incompatibilities (metallic implant). Data from two participants $(1 \mathrm{~m} ; 1 \mathrm{f})$ was rejected due to excessive motion in the scanner. For the fifteen remaining subjects, SNR was adequate (19.54, 95\% CI 18.24-20.84) and linewidth and mean error estimate of glutamate fit were low $(3.80 \mathrm{~Hz}, 95 \%$ CI 3.20-4.42; 4\%, 95\% CI 3.99-4.00, respectively). Tissue measures were individually estimated for metabolite quantification (Across subjects (mean, SD): WM $=0.27 \pm 0.06$ range $=0.20-0.45 ; \mathrm{GM}=0.59 \pm 0.04$ range $=0.50-0.66 ; \mathrm{CSF}=0.12 \pm 0.05$ range $=0.04-0.23)$. In two subjects, 1 MRS acquisition time point had to be excluded due to excessive motion, as evidenced by a large shot to shot variations in the NAA peak frequency location and linewidth. Figure 4 represents baseline-subtracted spectra quality parameters for the 3 different conditions within the functional scan to illustrate the quality metrics remained the constant throughout testing. Table 1 summarizes average metabolites for baseline and fMRS scans. The average reported pain intensity rating during heat was $3.8 \pm 2.0$, and $4.2 \pm 1.9$ during post-heat. Individual pain ratings, glutamate and Glx concentrations during the 20-min fMRS are illustrated in Fig. 5.

Neurochemical concentrations at pain onset. Glutamate and Glx concentrations both showed similar sizes in percent increases at the onset of pain (Glutamate: $+8.38 \%, \mathrm{t}=2.04, \mathrm{p}=0.06$; Glx: $+7.25 \%, \mathrm{t}=1.74, \mathrm{p}=0.11$ ) (Fig. 6). The change in glutamate and Glx correspond to large to medium effect sizes (Cohen's $\mathrm{d}_{\text {glutamate }}=0.74 \mathrm{CI}$ -0.05 to 1.55 ; Cohen's $\mathrm{d}_{\mathrm{Glx}}=0.60 \mathrm{CI}=-0.18$ to 1.40 ). There was no significant correlation between the change in glutamate or Glx concentrations and pain ratings (rest vs. pain onset) (Glutamate: $r=-0.36, p=0.18$; Glx: $\mathrm{r}=-0.22, \mathrm{p}=0.42)$. $\mathrm{tCr}$ concentrations tended to increase at the onset of pain $(+6.0 \%, \mathrm{t}=2.06, \mathrm{p}=0.05$; Cohen's $\mathrm{d}_{\mathrm{tCr}}=0.83 \mathrm{CI}=0.02-1.64$ ) (Fig. 6). NAA concentrations were unchanged from the onset of pain compared to rest $\left(+2.81 \%, \mathrm{t}=0.9, \mathrm{p}=0.34\right.$; Cohen's $\mathrm{d}_{\mathrm{NAA}}=0.28 \mathrm{CI}-0.49$ to 1.05$)$. There was no significant change in the water amplitude $(-3.0 \%, \mathrm{t}=1.45, \mathrm{p}=0.17$, Cohen's $\mathrm{d}=0.18)$ nor $\mathrm{T} 2 *(0.36 \%, \mathrm{t}=-0.42, \mathrm{p}=0.67$, Cohen's $\mathrm{d}=-0.02)$ values during rest and pain onset.

An exploratory analysis of sex revealed there was no difference in glutamate and Glx concentrations at rest (Glutamate: $\mathrm{t}=-0.05$, $\mathrm{p}$-value $=0.95, \mathrm{CI}-1.39$ to 1.32 , Cohen's $\mathrm{d}=0.02, \mathrm{CI}-1.22$ to 1.17; Glx: $\mathrm{t}=-1.17$, $\mathrm{p}$-value $=0.26, \mathrm{CI}-2.58$ to 0.76 , Cohen's $\mathrm{d}=0.59 \mathrm{CI}-1.82$ to 0.63 ), between males (Glutamate $=9.2 \pm 1.4$; $\mathrm{Glx}=13.5 \pm 1.6)$ and females (Glutamate $=9.2 \pm 0.9 ; \mathrm{Glx}=12.6 \pm 1.3)$. When examining changes at pain onset, large effect sizes were seen for glutamate in female participants $\left(+8.63 \%\right.$, Cohen's $\mathrm{d}_{\text {female }}=0.88$, CI -0.43 to $2.21)$, compared with medium sized effects in male participants $\left(+7.45 \%\right.$, Cohen's $\mathrm{d}_{\text {male }}=0.60 \mathrm{CI}-0.57$ to $1.73)$. Medium effect sizes are seen in Glx for both males and females $\left(+6.26 \%\right.$ Cohen's $d_{\text {female }}=0.58, C I-0.69$ 


\section{Pre-heat}

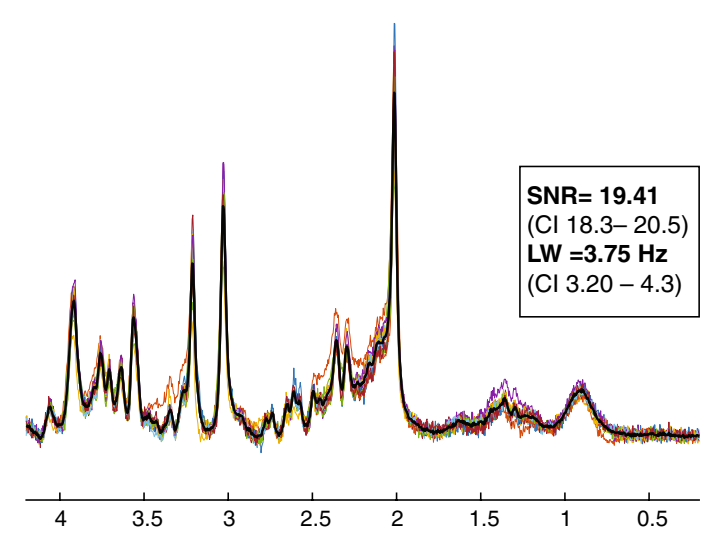

\section{Heat}

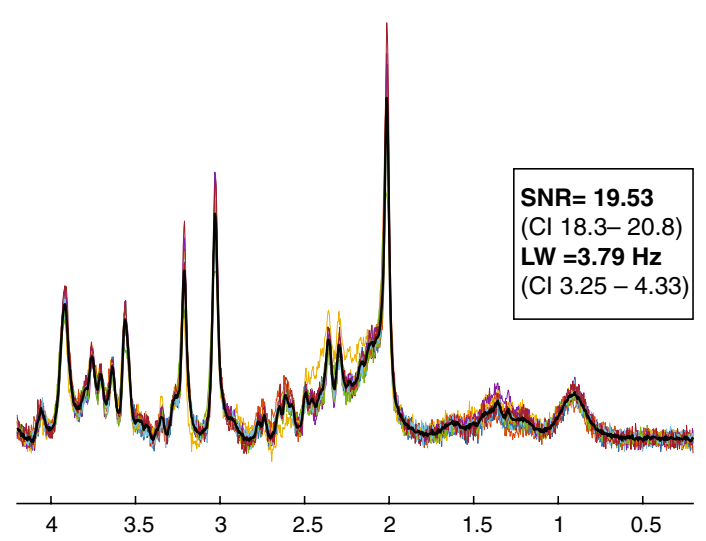

Post-heat

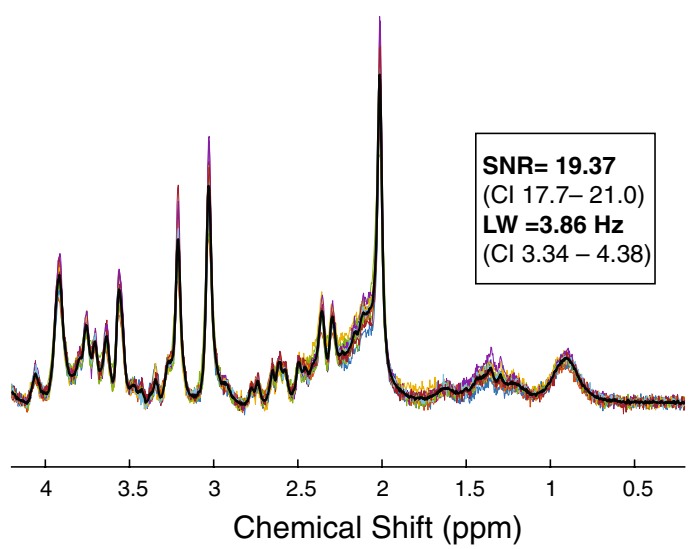

Figure 4. Overview of individual (coloured lines) and mean (black line) baseline-subtracted spectra of included data $(\mathrm{n}=15)$. The functional MRS scan series had 3 different condition (8-min pre-heat, 4-min heat, 8-min post-heat). A consistent high spectral quality was evidenced by high signal to noise ratio (SNR), and narrow line width (LW). 


\begin{tabular}{|c|c|c|c|c|c|c|c|c|c|c|c|}
\hline \multicolumn{12}{|l|}{ fMRS } \\
\hline Mean $(\mathrm{mM})$ & Baseline & 2 & 4 & 6 & 8 & 10 (heat) & 12 (heat) & 14 & 16 & 18 & 20 \\
\hline $\mathrm{tCr}$ & $7.65 \pm 0.15$ & $8.07 \pm 0.16$ & $7.69 \pm 0.15$ & $7.79 \pm 0.16$ & $7.63 \pm 0.15$ & $7.54 \pm 0.15$ & $7.62 \pm 0.15$ & $7.26 \pm 0.14$ & $7.81 \pm 0.16$ & $7.56 \pm 0.15$ & $7.67 \pm 0.15$ \\
\hline Glu & $9.90 \pm 0.42$ & $10.23 \pm 0.46$ & $9.54 \pm 0.43$ & $9.97 \pm 0.46$ & $9.73 \pm 0.43$ & $10.06 \pm 0.42$ & $9.82 \pm 0.43$ & $9.43 \pm 0.42$ & $9.92 \pm 0.42$ & $9.61 \pm 0.41$ & $9.79 \pm 0.41$ \\
\hline Glx & $14.06 \pm 0.55$ & $15.17 \pm 0.59$ & $13.54 \pm 0.52$ & $14.51 \pm 0.56$ & $13.86 \pm 0.56$ & $14.24 \pm 0.55$ & $13.96 \pm 0.54$ & $13.67 \pm 0.52$ & $14.41 \pm 0.53$ & $13.96 \pm 0.53$ & $13.95 \pm 0.55$ \\
\hline NAA & $9.41 \pm 0.26$ & $10.03 \pm 0.28$ & $9.60 \pm 0.26$ & $9.68 \pm 0.26$ & $9.71 \pm 0.25$ & $9.48 \pm 0.26$ & $9.49 \pm 0.26$ & $9.05 \pm 0.25$ & $9.71 \pm 0.26$ & $9.52 \pm 0.24$ & $9.58 \pm 0.26$ \\
\hline
\end{tabular}

Table 1. Mean MRS functional metabolite values in the Anterior Cingulate Cortex ( \pm CRLB mM). CRLB Cramer-Rao minimum lower bounds, $t C r$ total creatine; Glu glutamate; Glx glutamate + Glutamine; NAA $N$-Acetyl aspartic acid.

to $1.87 ;+8.04 \%$, Cohen's $\mathrm{d}_{\text {male }}=0.65, \mathrm{CI}-0.53$ to 1.83 ) (Fig. 6). At pain onset, the average NRS pain score was $2.9 \pm 0.9$ across all subjects, and was not significantly different for females $(3.0 \pm 0.8)$ compared to males $(2.8 \pm 1.1$; $\mathrm{t}=-0.24$, $\mathrm{p}$-value $=0.80, \mathrm{CI}-1.2$ to 0.9 ).

Neurochemical concentrations and pain intensity ratings. Based on a linear mixed effects analysis, glutamate and Glx concentrations were not significantly correlated with pain intensity ratings within subjects across the acquisition of fMRS (Glutamate: $\beta=0.059$ standard error $(\mathrm{SE})=0.06, \mathrm{p}=0.39$; Glx: $\beta=0.08 \mathrm{SE}=0.12$, $\mathrm{p}=0.48)($ Fig. 7$)$. This suggests that, overall, neither glutamate nor Glx concentrations modulated in relation to the perception of pain over the entire duration of the 20 -min functional scan. NAA and tCr were also not related to pain over the duration of our experiment (NAA: $\beta=-0.05$ standard error $(\mathrm{SE})=0.04, \mathrm{p}=0.24 ; \mathrm{tCr}: \beta=-0.01$ $\mathrm{SE}=0.05, \mathrm{p}=0.83$ ).

\section{Discussion}

In the current study, the relationship between glutamate and Glx in the ACC and perception of noxious heat stimulation was examined using fMRS. Medium to large effect sizes were detected for increases in glutamate, $\mathrm{Glx}$, and $\mathrm{tCr}$ at the transition to pain (i.e., pain onset, when NRS pain score $\geq 2$ for the first time). NAA, but not creatine remained stable at the onset of pain. There was no overall relationship between pain ratings and glutamate or Glx concentrations, indicating the transient nature of increased concentrations. Our observations suggest a role for glutamate in the ACC in initially detecting but not tracking pain.

Glutamate and GIx concentrations changes in the ACC. Evidence of regional activation in the ACC in response to noxious stimulation dates back to seminal studies applying fMRI and PET ${ }^{27,59-61}$. These are further supported by observations from single neuron recordings, which first raised the notion that a region of the ACC was selective for pain ${ }^{62,63}$. Subsequent investigations have demonstrated a more complex role, with the ACC, critically involved in "salience detection" ${ }^{64,65}$ and affective dimensions of pain ${ }^{59}$. On the basis that the ACC represents a prominent area of the "neurological signature of pain" responsive to analgesic interventions ${ }^{11,66,67}$, it remains a high priority area of study for pain researchers.

Five studies have previously investigated changes in glutamate and Glx in the ACC during the presentation of a noxious stimulus ${ }^{16,21,47-49}$, of which two have observed an increase in $\mathrm{Glx}^{16,21}$ and glutamate ${ }^{16}$. Similar to Mullins et.al, we applied a long-duration noxious stimulus and observed a similar percent increase in glutamate compared to rest $(+8.3 \%$ compared to Mullins et al. $+9.4 \%)$. To our knowledge, ours is the first study to distinguish the onset of pain from tonic appraisal. Based on our results, glutamatergic activation turns "on" independent of the intensity and "off" in the presence of a stimulus that remains painful. The lack of prolonged increases in glutamate concentrations contrasts that overserved for $\mathrm{PMRI}$ in various brain regions, including the mid-ACC, where BOLD remains elevated for the duration of the painful stimulation ${ }^{68}$. In agreement with our observations, a transient increase in extracellular glutamate in the $\mathrm{ACC}^{69}$ and elsewhere in the CNS (e.g., spinal $\operatorname{cord}^{25,28,70-75}$ ) has been reported in animal models using microdialysis following noxious stimulation induced by way of formalin injection. Critically, in response to formalin, the second wave of pain behaviour is not matched with an increase in extracellular glutamate, as is observed for the initial wave of pain behaviour. Collectively, this points to the glutamatergic response to noxious stimulation, captured by way of fMRS, representing one of the numerous "other" roles of the ACC in appraising sensory stimuli ${ }^{64,65,76,77}$.

Mechanisms underlying the tendency for glutamate to increase in response to noxious stimulation are, at this time, poorly understood. Glutamatergic synapses play a role in sensory transmission, including pain ${ }^{25,26,28,78-80}$. In the ACC, all major forms of ionotropic and metabotropic glutamate receptors have been isolated ${ }^{81,82}$. Metabolically, glutamate is stored as glutamine in astrocytes, and the balanced cycling between these two neurochemical is essential for normal functioning of brain cells ${ }^{83}$. In addition to functioning as a neurotransmitter, glutamate also serves as a metabolic precursor ${ }^{83}$. Glutamate and glutamine are compartmentalized in neurons and glia, respectively ${ }^{84}$ and are directly connected to neurotransmission and energy metabolism ${ }^{85,86}$.

Preliminary evidence suggests that glutamate levels may reflect neurotransmission ${ }^{19}$. One practical example is that NMDA antagonists significantly and paradoxically increase glutamate levels in the brain ${ }^{40}$. This could be explained for by NMDA receptor antagonists acting on post-synaptic neurons, preventing binding of glutamate, which increases the visibility of glutamate molecules to MRS (i.e., molecular tumbling rates). Available evidence suggests that glutamate in different locations in the neuron can be more or less visible to MRS depending on acquisition parameters $^{87}$. A longer echo time $(\mathrm{TE}>15 \mathrm{~ms})$ is more sensitive to compartmental shift (i.e., neural 

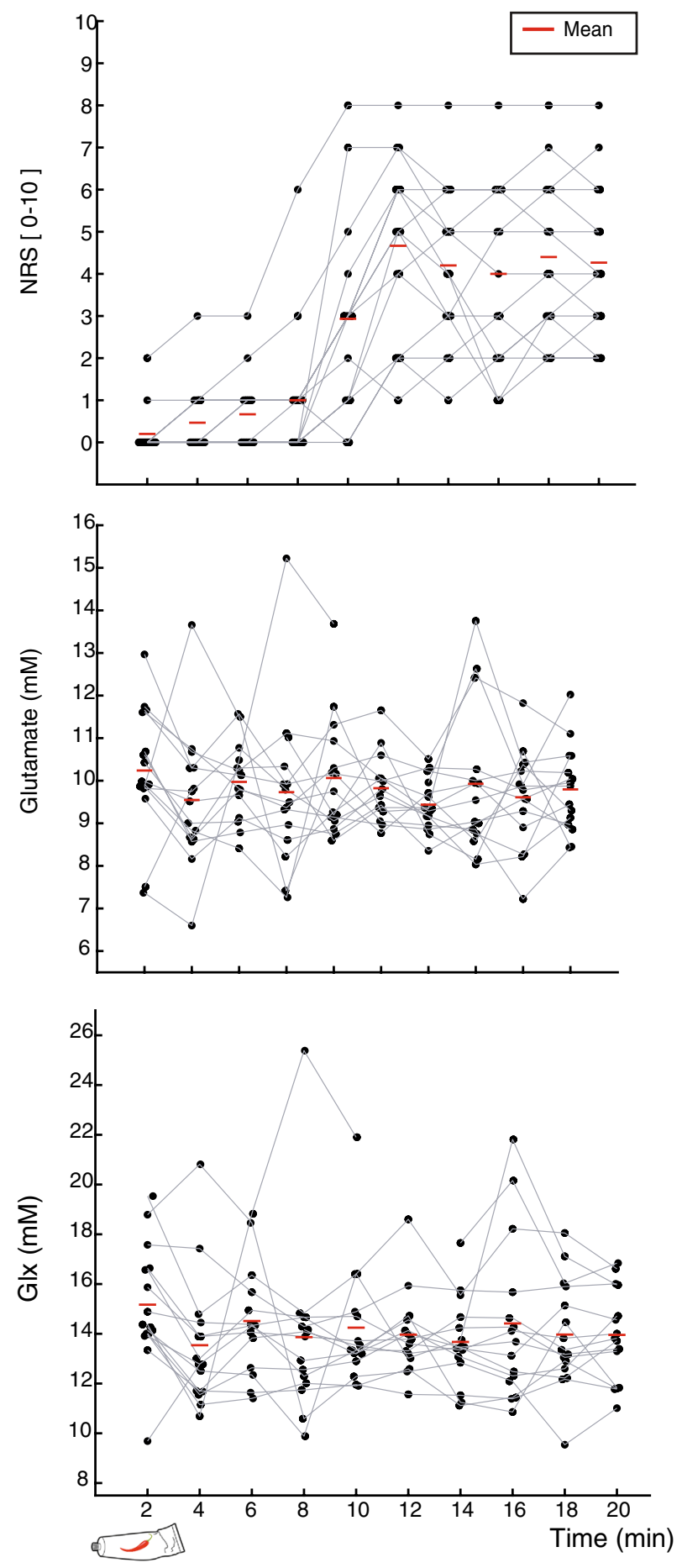

Figure 5. Pain intensity ratings (NRS) and glutamate and Glx concentrations. Values during the functional scan $(\mathrm{n}=15)$.

activity), compared to tightly packed glutamate in presynaptic vesicles ${ }^{19,87}$. The increased sensitivity of a change in compartmentation is due to a slower $\mathrm{T}_{2}$ relaxation rate-the rate at which MRS signal decays over time, as glutamate is freely floating (i.e., not packed in the vesicle). This theory is highlighted by a recent meta-analysis comparing fMRS studies with short and long echo times; with short echo time experiments demonstrating smaller increases in glutamate in response to sensory stimulation compared to longer echo times $(\sim 2.7$ versus $6.4 \%)^{19}$. Our study used an echo time of $22 \mathrm{~ms}$. Based on the aforementioned theory, the MRS signal may be more sensitive to glutamate levels moving from the presynaptic neuron to the postsynaptic neuron (i.e., compartmental shift). 

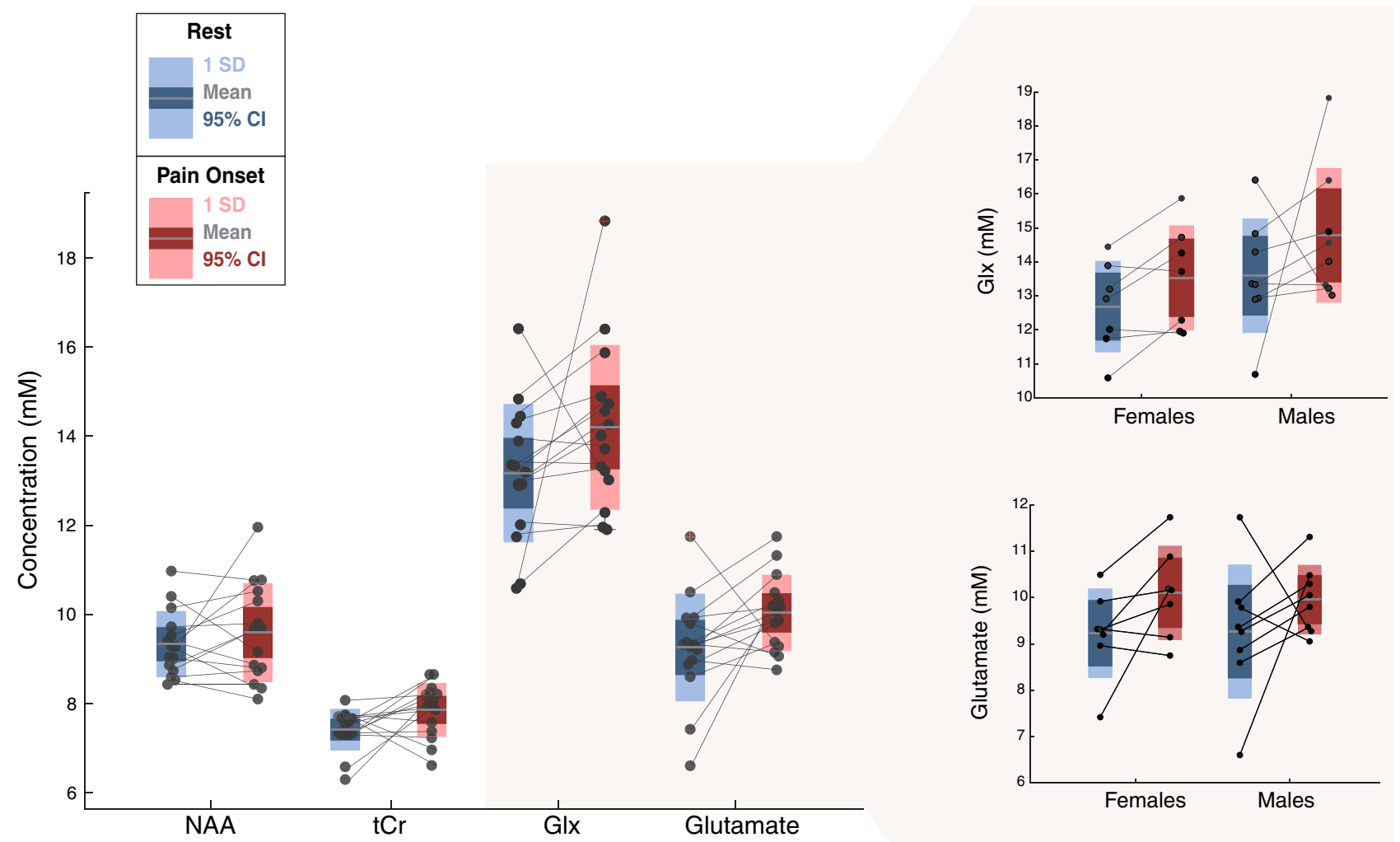

Figure 6. NAA, tCr, Glx and Glu ACC concentrations during rest (no pain perception) and pain onset for each volunteer $(n=15)$. Exploratory sex-based analysis showed a large effect for change in glutamate at pain onset in females (Cohen's $\mathrm{d}=0.88, \mathrm{CI}-0.43$ to $2.21, \mathrm{n}=7$ ), compared with a medium sized effect for males (Cohen's $\mathrm{d}=0.60 \mathrm{CI}-0.57$ to $1.73, \mathrm{n}=8$ ). Changes in Glx at pain onset were medium sized for both men (Cohen's $\mathrm{d}=0.65$ $\mathrm{CI}-0.53$ to 1.83 ) and women (Cohen's $\mathrm{d}=0.58 \mathrm{CI}-0.69$ to 1.87 ). There was no difference in pain rating at onset between men and women $(\mathrm{t}=-0.24$, $\mathrm{p}$-value $=0.80 \mathrm{CI}-1.2$ to 0.9$)$.
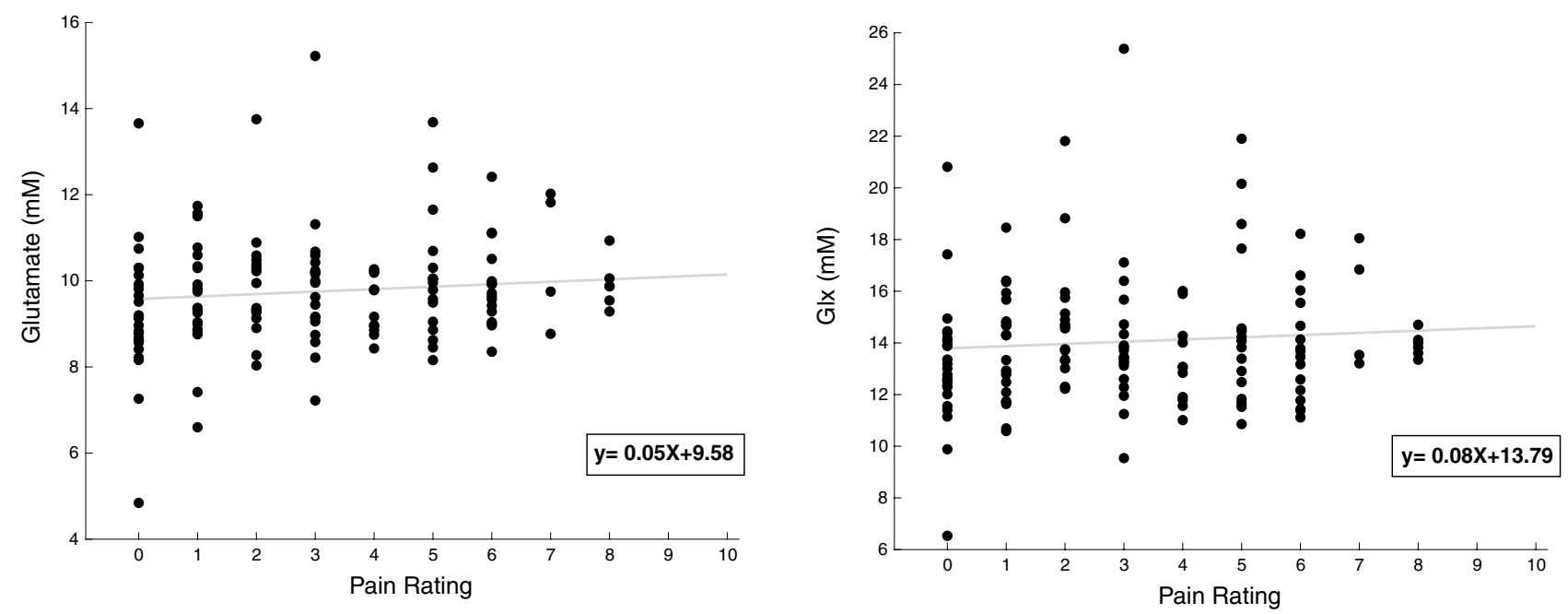

Figure 7. Linear mixed effects model during the $20 \mathrm{~min}$ fMRS scan. There was no relationship within subjects over the entire duration of data acquisition between pain rating and glutamate or Glx. 
Other metabolites. Our analysis focused on examining glutamate and Glx. Other metabolites such as NAA and tCr, which have more prominent resonances, were examined as a reference, to establish the specificity of changes in glutamate in response to pain. NAA was selected from other potential metabolites because turnover is slow, and is not responsive to acute metabolic disturbances ${ }^{41}$ and as expected, concentrations remained stable, even at the onset of pain. Creatine, interestingly, increased in response to pain and did so similarly to glutamate and Glx. A previous study also reported a dynamic $\mathrm{tCr}$ response following noxious stimulation albeit a decrease ${ }^{51}$. Fluctuations in creatine concentrations are a major concern because tCr levels are commonly used as a reference in H-MRS (i.e., creatine ratios) ${ }^{88}$, including in functional studies ${ }^{21,34,47,50}$. While the essential role of creatine in energy metabolism and cell energetics is well-established ${ }^{89}$, emerging evidence suggests a role in neuromodulation and neurotransmission ${ }^{89-93}$. The mechanisms underlying changes in $\mathrm{tCr}$ in response to pain require further elucidation, our observations, as well as those previously published ${ }^{51}$, raise concerns about the functional stability of creatine in task-related MRS studies.

Sex effects. In an exploratory secondary analysis, we investigated the effect of sex on changes in glutamate and Glx in response to pain. This analysis reflects a high priority area in pain research ${ }^{94}$, and a commitment to understanding the role of sex in biomedical research ${ }^{95}$. Various neuroimaging techniques have been employed to probe sex differences in the brain, revealing prominent variations in anatomy and function ${ }^{96}$. However, recent meta-research has suggested that a reporting bias may overestimate the magnitude of sex-related differences in the brain ${ }^{97}$. With regards to MRS, sex-related differences in resting glutamate levels have been reported in various brain areas (e.g., hippocampus) but not in the $\mathrm{ACC}^{98}$. To our knowledge, studies applying noxious stimulation during the acquisition of fMRS have not previously examined or reported differences related to sex. Our results confirm similar resting glutamate and Glx concentrations in the ACC between men and women and nominally larger increases in glutamate and Glx in response to pain in women. Sex differences in glutamatergic signalling have also been reported in animal models ${ }^{99}$, with female rats tending to be more sensitive to NMDA receptor modulation (e.g. Ketamine ${ }^{100-102}$. Further fMRS research should incorporate sex-based analyses to gain a better understanding of glutamatergic signalling in humans.

Limitations and future directions. The most notable limitation of our study a small sample size $(\mathrm{n}=15)$. To account for this, we have reported the results of conventional significance testing, as well as effect sizes for all relevant comparisons. Future studies should include a larger sample of men and women to further distinguish the role of excitation in the ACC in response to pain. Another limitation of our study is that we did not acquire GABA edited spectra. Previous fMRS studies have demonstrated the capacity to acquire estimates of GABA ${ }^{21,50}$, one of which has demonstrated reduced concentrations following the presentation of a noxious stimulus ${ }^{21}$. Reduced GABA concentrations are in agreement with our observations, insofar as this reflects increased excitation. Finally, the field of MRS is rapidly evolving, and new methods of acquisition have emerged. Recent guidelines suggest the localization sequence semi-LASER offers reduced localization error (reducing chemical shift displacement) compared to PRESS ${ }^{15}$. The incorporation of simulated metabolite basis sets into the routine analysis is recommended for capturing the full spectral detail from short TE acquisitions ${ }^{15}$, future studies should aim to incorporate these suggestions.

\section{Conclusion}

In summary, healthy participants undergoing tonic noxious stimulation demonstrated increased concentrations of glutamate and Glx at the onset of pain. Subsequent reports of pain were not accompanied by increased glutamate or Glx concentrations. We propose a role for glutamate in ACC related to the detection of a noxious stimulus.

\section{Data availability}

The datasets generated during and/or analysed during the current study are available from the corresponding author on reasonable request.

Received: 2 April 2020; Accepted: 14 October 2020

Published online: 05 November 2020

\section{References}

1. Schweinhardt, P. \& Bushnell, C. Pain imaging in health and diease- how far have we come?. J. Clin. Investig. 120, 3788-3797 (2010).

2. Peyron, R. \& Fauchon, C. Functional imaging of pain. Rev. Neurol. 1, 8. https://doi.org/10.1016/j.neurol.2018.08.006 (2018).

3. Selvarajah, D. et al. Structural and functional abnormalities of the primary somatosensory cortex in diabetic peripheral neuropathy: a multimodal MRI study. Diabetes 68, 796-806 (2019).

4. Mouraux, A. \& Iannetti, G. D. The search for pain biomarkers in the human brain. Brain https://doi.org/10.1093/brain/awy28 $1(2018)$

5. Hansen, T. M. et al. Characterization of cortical source generators based on electroencephalography during tonic pain. J. Pain Res. 10, 1401-1409 (2017)

6. Nickel, M. M. et al. Autonomic responses to tonic pain are more closely related to stimulus intensity than to pain intensity. Pain 158, 2129-2136 (2017).

7. Hüllemann, P. et al. Peripheral sensitization reduces laser-evoked potential habituation. Neurophysiol. Clin. 45, 457-467 (2015).

8. Valentini, E., Nicolardi, V. \& Aglioti, S. M. Painful engrams: Oscillatory correlates of working memory for phasic nociceptive laser stimuli. Brain Cogn. 115, 21-32 (2017).

9. Baillet, S. Magnetoencephalography for brain electrophysiology and imaging. Nat. Neurosci. 20, 327-339 (2017). 
10. Nickel, M. M. et al. Brain oscillations differentially encode noxious stimulus intensity and pain intensity. Neuroimage 148, 141-147 (2017).

11. Wager, T. D. et al. An fMRI-based neurologic signature of physical pain. N. Engl. J. Med. 368, 1388-1397 (2013).

12. Zunhammer, M., Bingel, U. \& Wager, T. D. Placebo effects on the neurologic pain signature: a meta-analysis of individual participant functional magnetic resonance imaging data. JAMA Neurol. 75, 1321-1330 (2018).

13. Brooks, J. C. W., Zambreanu, L., Godinez, A., Craig, A. D. \& Tracey, I. Somatotopic organisation of the human insula to painful heat studied with high resolution functional imaging. Neuroimage 27, 201-209 (2005).

14. Davis, K. D., Pope, G. E., Crawley, A. P. \& Mikulis, D. J. Neural correlates of prickle sensation: a percept-related fMRI study. Nat. Neurosci. 5, 1121-1122 (2002).

15. Wilson, M. et al. A methodological consensus on clinical proton MR spectroscopy of the brain: review and recommendations. Magn. Reson. Med. https://doi.org/10.1002/mrm.27742 (2019).

16. Mullins, P. G., Rowland, L. M., Jung, R. E. \& Sibbitt, W. L. A novel technique to study the brain's response to pain: Proton magnetic resonance spectroscopy. Neuroimage 26, 642-646 (2005).

17. Apšvalka, D., Gadie, A., Clemence, M. \& Mullins, P. G. Event-related dynamics of glutamate and BOLD effects measured using functional magnetic resonance spectroscopy (fMRS) at 3T in a repetition suppression paradigm. Neuroimage 118, 292-300 (2015).

18. Mangia, S., Giove, F. \& DiNuzzo, M. Metabolic pathways and activity-dependent modulation of glutamate concentration in the human brain. J. Phys. Conf. Ser. 282, 2554-2561 (2011).

19. Mullins, P. G. Towards a theory of functional magnetic resonance spectroscopy (fMRS): a meta-analysis and discussion of using MRS to measure changes in neurotransmitters in real time. Scand. J. Psychol. 59, 91-103 (2018).

20. Taylor, R. et al. Functional magnetic resonance spectroscopy of glutamate in schizophrenia and major depressive disorder: anterior cingulate activity during a color-word Stroop task. npj Schizophr. 1, 15028 (2015).

21. Cleve, M., Gussew, A. \& Reichenbach, J. R. In vivo detection of acute pain-induced changes of GABA+ and Glx in the human brain by using functional 1H MEGA-PRESS MR spectroscopy. Neuroimage 105, 67-75 (2014).

22. Gussew, A., Rzanny, R., Güllmar, D., Scholle, H. C. \& Reichenbach, J. R. 1H-MR spectroscopic detection of metabolic changes in pain processing brain regions in the presence of non-specific chronic low back pain. Neuroimage 54, 1315-1323 (2011).

23. Bednařík, P. et al. Neurochemical and BOLD responses during neuronal activation measured in the human visual cortex at 7 Tesla. J. Cereb. Blood Flow Metab. 35, 601-610 (2015).

24. Zhu, H. \& Barker, P. B. MR spectroscopy and spectroscopic imaging of the brain. Methods Mol. Biol. https://doi.org/10.1007/9781-61737-992-5_9 (2010).

25. Okuda, K., Sakurada, C., Takahashi, M., Yamada, T. \& Sakurada, T. Characterization of nociceptive responses and spinal releases of nitric oxide metabolites and glutamate evoked by different concentrations of formalin in rats. Pain 92, 107-115 (2001).

26. Silva, E., Hernandez, L., Contreras, Q., Guerrero, F. \& Alba, G. Noxious stimulation increases glutamate and arginine in the periaqueductal gray matter in rats: A microdialysis study. Pain 87, 131-135 (2000).

27. Vogt, B. A., Derbyshire, S. \& Jones, A. K. P. Pain processing in four regions of human cingulate cortex localized with co-registered PET and MR imaging. Eur. J. Neurosci. https://doi.org/10.1111/j.1460-9568.1996.tb01608.x (1996).

28. Vetter, G., Geisslinger, G. \& Tegeder, I. Release of glutamate, nitric oxide and prostaglandin E2 and metabolic activity in the spinal cord of rats following peripheral nociceptive stimulation. Pain 92, 213-218 (2001).

29. Harris, R. E. et al. Dynamic levels of glutamate within the insula are associated with improvements in multiple pain domains in fibromyalgia. Arthritis Rheum. 58, 903-907 (2008).

30. Harris, R. E. et al. Pregabalin rectifies aberrant brain chemistry, connectivity, and functional response in chronic pain patients. Anesthesiology 119, 1453-1464 (2013).

31. Zunhammer, M. et al. Combined glutamate and glutamine levels in pain-processing brain regions are associated with individual pain sensitivity. Pain 157, 1 (2016).

32. Franklin, T. R. et al. Acute baclofen diminishes resting baseline blood flow to limbic structures: a perfusion fMRI study. Drug Alcohol Depend. 125, 60-66 (2012).

33. Gussew, A. et al. Time-resolved functional $1 \mathrm{H}$ MR spectroscopic detection of glutamate concentration changes in the brain during acute heat pain stimulation. Neuroimage 49, 1895-1902 (2010).

34. Gutzeit, A. et al. Insula-specific responses induced by dental pain. A proton magnetic resonance spectroscopy study. Eur. Radiol. 21, 807-815 (2011).

35. Archibald, J. et al. NeuroImage excitatory and inhibitory responses in the brain to experimental pain: a systematic review of MR spectroscopy studies. Neuroimage 215, 116794 (2020).

36. Ito, T. et al. Proton magnetic resonance spectroscopy assessment of metabolite status of the anterior cingulate cortex in chronic pain patients and healthy controls. J. Pain Res. 10, 287-293 (2017).

37. Feraco, P. et al. Metabolic abnormalities in pain-processing regions of patients with fibromyalgia: a $3 \mathrm{~T}$ MR spectroscopy study. AJNR Am. J. Neuroradiol. 32, 1585-1590 (2011).

38. Peek, A. L. et al. Brain GABA and glutamate levels across pain conditions: A systematic literature review and meta-analysis of $1 \mathrm{H}-\mathrm{MRS}$ studies using the MRS-Q quality assessment tool. Neuroimage https://doi.org/10.1016/j.neuroimage.2020.116532 (2020).

39. Staud, R., Vierck, C. J., Robinson, M. E. \& Price, D. D. Effects of the N-methyl-D-aspartate receptor antagonist dextromethorphan on temporal summation of pain are similar in fibromyalgia patients and normal control subjects. J. Pain https://doi.org/10.1016/j. jpain.2005.01.357 (2005)

40. Fayed, N. et al. Changes in metabolites after treatment with memantine in fibromyalgia. A double-blind randomized controlled trial with magnetic resonance spectroscopy with a 6-month follow-up. CNS Neurosci. Ther. 20, 999-1007 (2014).

41. de Graaf, R. A. In Vivo NMR Spectroscopy (Wiley, New York, 2019).

42. Svensson, P., Minoshima, S., Beydoun, A., Morrow, T. J. \& Casey, K. L. Cerebral processing of acute skin and muscle pain in humans. J. Neurophysiol. https://doi.org/10.1152/jn.1997.78.1.450 (1997).

43. Coghill, R. C. et al. Distributed processing of pain and vibration by the human brain. J. Neurosci. https://doi.org/10.1523/jneur osci.14-07-04095.1994 (1994).

44. Jones, A. K. P., Brown, W. D., Friston, K. J., Qi, L. Y. \& Frackowiak, R. S. J. Cortical and subcortical localization of response to pain in man using positron emission tomography. Proc. R. Soc. B Biol. Sci. https://doi.org/10.1098/rspb.1991.0048 (1991).

45. Misra, G., Wang, W., Archer, D. B., Roy, A. \& Coombes, S. A. Automated classification of pain perception using high-density electroencephalography data. J. Neurophysiol. 117, 786-795 (2017).

46. Novotny, E. J., Fulbright, R. K., Pearl, P. L., Gibson, K. M. \& Rothman, D. L. Magnetic resonance spectroscopy of neurotransmitters in human brain. Ann. Neurol. 54, 25-31 (2003).

47. Hansen, T. M., Olesen, A. E. \& Drewes, A. M. Cingulate metabolites during pain and morphine treatment as assessed by magnetic resonance spectroscopy. J. Pain 7, 269-276 (2014).

48. Chiappelli, J. et al. Glutamatergic response to heat pain stress in schizophrenia. Schizophr. Bull. https://doi.org/10.1093/schbu $1 /$ sbx133 (2017).

49. Kupers, R., Danielsen, E. R., Kehlet, H., Christensen, R. \& Thomsen, C. Painful tonic heat stimulation induces GABA accumulation in the prefrontal cortex in man. Pain 142, 89-93 (2009). 
50. Cleve, M., Gussew, A., Wagner, G., Bär, K. J. \& Reichenbach, J. R. Assessment of intra- and inter-regional interrelations between GABA+, Glx and BOLD during pain perception in the human brain: a combined1H fMRS and fMRI study. Neuroscience $\mathbf{3 6 5}$, $125-136$ (2017).

51. Gutzeit, A. et al. Differential NMR spectroscopy reactions of anterior/posterior and right/left insular subdivisions due to acute dental pain. Eur. Radiol. 23, 450-460 (2013).

52. Haase, A., Frahm, J., Hanicke, W. \& Matthaei, D. 1H NMR chemical shift selective (CHESS) imaging. Plasma Sources Sci. Technol. https://doi.org/10.1088/0031-9155/30/4/008 (1985).

53. MacMillan, E. L. et al. Progressive multiple sclerosis exhibits decreasing glutamate and glutamine over two years. Mult. Scler. J. 22, 112-116 (2016).

54. Zhang, Y., Brady, M. \& Smith, S. Segmentation of brain MR images through a hidden Markov random field model and the expectation-maximization algorithm. IEEE Trans. Med. Imaging 20, 45-57 (2001).

55. Liang, A. L. W. et al. Short-term stability of $\mathrm{T} 1$ and $\mathrm{T} 2$ relaxation measures in multiple sclerosis normal appearing white matter. J. Neurol. 259, 1151-1158 (2012).

56. Laule, C. et al. Long T2 water in multiple sclerosis: what else can we learn from multi-echo T2 relaxation?. J. Neurol. 254, 1579-1587 (2007).

57. de Graaf, R. A. In Vivo NMR Spectroscopy Principles and Techniques (Wiley, New York, 2007).

58. Cohen, J. Statistical Power Analysis for the Behavioral Sciences. Routledge. ISBN 978-1-134- (1988).

59. Rainville, P., Duncan, G. H., Price, D. D., Carrier, B. \& Bushnell, M. C. Pain affect encoded in human anterior cingulate but not somatosensory cortex. Science https://doi.org/10.1126/science.277.5328.968 (1997).

60. Davis, K. D., Taylor, S. J., Crawley, A. P., Wood, M. L. \& Mikulis, D. J. Functional MRI of pain- and attention-related activations in the human cingulate cortex. J. Neurophysiol. https://doi.org/10.1152/jn.1997.77.6.3370 (1997).

61. Casey, K. L., Minoshima, S., Morrow, T. J. \& Koeppe, R. A. Comparison of human cerebral activation patterns during cutaneous warmth, heat pain, and deep cold pain. J. Neurophysiol. https://doi.org/10.1152/jn.1996.76.1.571 (1996).

62. Hutchison, W. D., Davis, K. D., Lozano, A. M., Tasker, R. R. \& Dostrovsky, J. O. Pain-related neurons in the human cingulate cortex [2]. Nat. Neurosci. https://doi.org/10.1038/8065 (1999).

63. Sikes, R. W. \& Vogt, B. A. Nociceptive neurons in area 24 of rabbit cingulate cortex. J. Neurophysiol. https://doi.org/10.1152/ jn.1992.68.5.1720 (1992).

64. Davis, K. D. \& Moayedi, M. Central mechanisms of pain revealed through functional and structural MRI. J. Neuroimmune Pharmacol. https://doi.org/10.1007/s11481-012-9386-8 (2013).

65. Davis, K. D. et al. Human anterior cingulate cortex neurons encode cognitive and emotional demands. J. Neurosci. https://doi. org/10.1523/JNEUROSCI.2315-05.2005 (2005)

66. López-Solà, M., Geuter, S., Koban, L., Coan, J. A. \& Wager, T. D. Brain mechanisms of social touch-induced analgesia in females. Pain https://doi.org/10.1097/j.pain.0000000000001599 (2019).

67. Weber, K. A. et al. Evidence for decreased Neurologic Pain Signature activation following thoracic spinal manipulation in healthy volunteers and participants with neck pain. NeuroImage Clin. https://doi.org/10.1016/j.nicl.2019.102042 (2019).

68. Downar, J., Mikulis, D. J. \& Davis, K. D. Neural correlates of the prolonged salience of painful stimulation. Neuroimage https:// doi.org/10.1016/S1053-8119(03)00407-5 (2003).

69. Silva, E., Quiñones, B., Páez, X. \& Hernández, L. Efecto de una inyección de morfina sistémica sobre algunos aminoácidos en la corteza cingulada anterior en el dolor agudo. Invest. Clin. 49, 511-522 (2008).

70. Shi, L. et al. Formalin-induced spinal glutamate release in freely moving rats: comparison of two spinal microdialysis approaches. Acta Anaesthesiol. Belg. 55, 43-48 (2004)

71. Malmberg, A. B. \& Yaksh, T. L. The effect of morphine on formalin-evoked behaviour and spinal release of excitatory amino acids and prostaglandin E2 using microdialysis in conscious rats. Br. J. Pharmacol. https://doi.org/10.1111/j.1476-5381.1995. tb13315.x (1995).

72. Maimberg, A. B. \& Yaksh, T. L. Cyclooxygenase inhibition and the spinal release of prostaglandin E2and amino acids evoked by paw formalin injection: a microdialysis study in unanesthetized rats. J. Neurosci. https://doi.org/10.1523/jneurosci.15-04-02768 1995 (1995)

73. Vidal-Torres, A. et al. Effects of the selective sigma-1 receptor antagonist S1RA on formalin-induced pain behavior and neurotransmitter release in the spinal cord in rats. J. Neurochem. https://doi.org/10.1111/jnc.12648 (2014).

74. Vidal-Torres, A. et al. Evaluation of formalin-induced pain behavior and glutamate release in the spinal dorsal horn using in vivo microdialysis in conscious rats. J. Pharmacol. Sci. https://doi.org/10.1254/jphs.12105SC (2012).

75. Watanabe, C., Mizoguchi, H., Bagetta, G. \& Sakurada, S. The involvement of the spinal release of glutamate and nitric oxide in peripheral noxious stimulation-induced pain-related behaviors-Study in mouse spinal microdialysis. Neurosci. Lett. https://doi. org/10.1016/j.neulet.2012.02.091 (2012).

76. Etkin, A., Egner, T. \& Kalisch, R. Emotional processing in anterior cingulate and medial prefrontal cortex. Trends Cogn. Sci. https://doi.org/10.1016/j.tics.2010.11.004 (2011).

77. Schneider, M., Leuchs, L., Czisch, M., Sämann, P. G. \& Spoormaker, V. I. Disentangling reward anticipation with simultaneous pupillometry / fMRI. Neuroimage https://doi.org/10.1016/j.neuroimage.2018.04.078 (2018).

78. Zhuo, M. Molecular mechanisms of pain in the anterior cingulate cortex. J. Neurosci. Res. 259, 250-259 (2006).

79. Zhuo, M. Ionotropic glutamate receptors contribute to pain transmission and chronic pain. Neuropharmacology https://doi. org/10.1016/j.neuropharm.2016.08.014 (2017).

80. Sluka, K. A. \& Willis, W. D. Increased spinal release of excitatory amino acids following intradermal injection of capsaicin is reduced by a protein kinase G inhibitor. Brain Res. 798, 281-286 (1998).

81. Koga, K., Li, S. \& Zhuo, M. Metabotropic glutamate receptor dependent cortical plasticity in chronic pain. Curr. Neuropharmacol. https://doi.org/10.2174/1570159x13666150425002304 (2015).

82. Koga, K. et al. Coexistence of two forms of LTP in ACC provides a synaptic mechanism for the interactions between anxiety and chronic pain. Neuron https://doi.org/10.1016/j.neuron.2014.12.021 (2015).

83. Schousboe, A. Metabolic signaling in the brain and the role of astrocytes in control of glutamate and GABA neurotransmission. Neurosci. Lett. https://doi.org/10.1016/j.neulet.2018.01.038 (2019).

84. Ramadan, S., Lin, A. \& Stanwell, P. Glutamate and glutamine: a review of in vivo MRS in the human brain. NMR Biomed. 26, 1-27 (2013).

85. Escartin, C., Valette, J., Lebon, V. \& Bonvento, G. Neuron-astrocyte interactions in the regulation of brain energy metabolism: a focus on NMR spectroscopy. J. Neurochem. https://doi.org/10.1111/j.1471-4159.2006.04083.x (2006).

86. Sibson, N. R. et al. Stoichiometric coupling of brain glucose metabolism and glutamatergic neuronal activity. Proc. Natl. Acad. Sci. USA https://doi.org/10.1073/pnas.95.1.316 (1998).

87. Kauppinen, R. A., Pirttilä, T. R., Auriola, S. O. \& Williams, S. R. Compartmentation of cerebral glutamate in situ as detected by 1H/13C n.m.r. Biochem. J. 298, 121-127 (1994).

88. Soreni, N. et al. Intraindividual variability of striatal 1H-MRS brain metabolite measurements at 3 T. Magn. Reson. Imaging https ://doi.org/10.1016/j.mri.2005.10.027 (2006).

89. Rackayova, V., Cudalbu, C., Pouwels, P. J. W. \& Braissant, O. Creatine in the central nervous system: from magnetic resonance spectroscopy to creatine deficiencies. Anal. Biochem. 529, 144-157 (2017). 
90. Koga, Y. et al. Brain creatine functions to attenuate acute stress responses through GABAnergic system in chicks. Neuroscience 132, 65-71 (2005).

91. Neu, A. et al. Activation of GABAA receptors by guanidinoacetate: a novel pathophysiological mechanism. Neurobiol. Dis. 11, 298-307 (2002).

92. Van De Kamp, J. M., Jakobs, C., Gibson, K. M. \& Salomons, G. S. New insights into creatine transporter deficiency: the importance of recycling creatine in the brain. J. Inherit. Metab. Dis. 36, 155-156 (2013).

93. Almeida, L., Salomons, G., Hogenboom, F., Jakobs, C. \& Schoffelmeer, A. Exocytotic release of creatine in rat brain. Synapse 346, 319-346 (2006).

94. Musey, P. I. et al. Gender differences in acute and chronic pain in the emergency department: results of the 2014 academic emergency medicine consensus conference pain section. Acad. Emerg. Med. https://doi.org/10.1111/acem.12529 (2014).

95. Lee, S. K. Sex as an important biological variable in biomedical research. BMB Rep. https://doi.org/10.5483/BMBRe p.2018.51.4.034 (2018).

96. Ritchie, S. J. et al. Sex differences in the adult human brain: evidence from 5216 UK biobank participants. Cereb. Cortex https ://doi.org/10.1093/cercor/bhy109 (2018).

97. David, S. P. et al. Potential reporting bias in neuroimaging studies of sex differences. Sci. Rep. https://doi.org/10.1038/s4159 8-018-23976-1 (2018)

98. Hädel, S., Wirth, C., Rapp, M., Gallinat, J. \& Schubert, F. Effects of age and sex on the concentrations of glutamate and glutamine in the human brain. J. Magn. Reson. Imaging 38, 1480-1487 (2013).

99. Wickens, M. M., Bangasser, D. A. \& Briand, L. A. Sex differences in psychiatric disease: a focus on the glutamate system. Front. Mol. Neurosci. 11, 1-12 (2018).

100. Wozniak, D. F. et al. Disseminated corticolimbic neuronal degeneration induced in rat brain by MK-801: potential relevance to Alzheimer's disease. Neurobiol. Dis. 5, 305-322 (1998).

101. McDougall, S. A., Moran, A. E., Baum, T. J., Apodaca, M. G. \& Real, V. Effects of ketamine on the unconditioned and conditioned locomotor activity of preadolescent and adolescent rats: impact of age, sex, and drug dose. Psychopharmacology 234, 2683-2696 (2017).

102. Wang, Y. et al. Prenatal chronic mild stress induces depression-like behavior and sex-specific changes in regional glutamate receptor expression patterns in adult rats. Neuroscience 301, 363-374 (2015).

\section{Acknowledgements}

J. Archibald is supported by a research scholarship of the National Council of Science and Technology (CONACYT), GSM-NSERC and the Michel Smith foreign study supplement (MSFSS). E.L MacMillan receives salary support from Philips Canada. J. Kramer is funded by an NSERC Discovery Grant. All authors have no conflicts of interest to declare (financial or otherwise).

\section{Author contributions}

J.A.: Conceptualization, methodology, software, validation, visualization and writing original draft. E.L.M.: Conceptualization, methodology, sortware, validation, writing-review and editing. C.C.: Methodology and software. K.P.: Conceptualization, methodology, writing-review and editing. C.L.: Conceptualization, writing-review and editing. J.L.K.K.: Conceptualization, methodology, validation, writing-review and editing.

\section{Competing interests}

The authors declare no competing interests.

\section{Additional information}

Correspondence and requests for materials should be addressed to J.A.

Reprints and permissions information is available at www.nature.com/reprints.

Publisher's note Springer Nature remains neutral with regard to jurisdictional claims in published maps and institutional affiliations.

(c) (i) Open Access This article is licensed under a Creative Commons Attribution 4.0 International License, which permits use, sharing, adaptation, distribution and reproduction in any medium or format, as long as you give appropriate credit to the original author(s) and the source, provide a link to the Creative Commons licence, and indicate if changes were made. The images or other third party material in this article are included in the article's Creative Commons licence, unless indicated otherwise in a credit line to the material. If material is not included in the article's Creative Commons licence and your intended use is not permitted by statutory regulation or exceeds the permitted use, you will need to obtain permission directly from the copyright holder. To view a copy of this licence, visit http://creativecommons.org/licenses/by/4.0/.

(C) The Author(s) 2020 